\title{
CARACTERIZAÇÃO DO COORDENADOR PEDAGÓGICO A PARTIR DE TESES DO CÁTALOGO DE TESES E DISSERTAÇÕES DA CAPES
}

\author{
Rocheli Regina Predebon Silveira \\ Agnaldo Mesquita de Lima Junior \\ Maurício Aires Vieira
}

Resumo

Este trabalho buscou compreender como se caracteriza a figura do coordenador pedagógico em teses de doutorado. Para isso, realizamos uma pesquisa do tipo "Estado da arte", utilizando o Catálogo de Teses e Dissertações - Capes, com o descritor de pesquisa "coordenador pedagógico", entre aspas para melhor delimitar a pesquisa. Utilizamos este repositório pois ele abarca toda a produção nacional de pós-graduação em nível de mestrado e doutorado. Analisamos os trabalhos resultantes de teses de doutorado, pois este é o maior nível de pós-graduação e que podem ser mais relevantes para compor nossa análise. Assim, foi possível localizar 45 pesquisas. Dessas, 27 fugiram da temática e 4 não puderam ser lidas na sua completude, restando para análise 14 produções. As pesquisas foram divididas pelos resumos em 3 categorias: "coordenador pedagógico e sua relação com a formação docente", "o trabalho cotidiano do coordenador pedagógico" e "políticas públicas e atuação do coordenador pedagógico".

Palavras-chave: coordenador pedagógico; formação docente; estado da arte.

\section{CHARACTERIZATION OF THE PEDAGOGICAL COORDINATOR FROM THE THESIS OF THE CAPES THESIS AND DISSERTATIONS CATALOG}

Abstract

This work sought to understand how the figure of the pedagogical coordinator is characterized in doctoral theses. For this, we carried out a research of the "State of the art" type, using the Theses and Dissertations Catalog - Capes, with the research descriptor "pedagogical coordinator", in quotation marks to better delimit the research. We use this repository because it encompasses the entire national production of postgraduate studies at the master's and doctoral level. We analyzed the works resulting from doctoral theses, as this is the highest level of postgraduate studies and which may be more relevant to compose our analysis. Thus, it was possible to locate 45 searches. Of these, 27 escaped from the theme and 4 could not be read in its entirety, leaving 14 productions for analysis. The surveys were divided by abstracts into 3 categories: "pedagogical coordinator and its relationship with teacher education", "the daily work of the pedagogical coordinator" and "public policies and the role of the pedagogical coordinator".

Keywords: pedagogical coordinator; teacher training; state of art .

\section{CARACTERIZACIÓN DEL COORDINADOR PEDAGÓGICO A PARTIR DE LA TESIS DEL CATÁLOGO DE TESIS Y DISERTACIONES DE LA CAPES}

Resumen

Este trabajo buscó comprender cómo se caracteriza la figura del coordinador pedagógico en las tesis doctorales. Para ello, se realizó una investigación del tipo "Estado del arte", utilizando el Catálogo de Tesis y Disertaciones - Capes, con el descriptor de investigación "coordinador pedagógico", entre comillas para delimitar mejor la investigación. Utilizamos este repositorio porque engloba toda la producción nacional de 
estudios de posgrado a nivel de maestría y doctorado. Analizamos los trabajos resultantes de las tesis doctorales, por ser este el nivel más alto de estudios de posgrado y que pueden ser más relevantes para componer nuestro análisis. Así, fue posible localizar 45 búsquedas. De estas, 27 escaparon de la temática y 4 no pudieron leerse en su totalidad, quedando 14 producciones para su análisis. Las encuestas se dividieron por resúmenes en 3 categorías: "coordinador pedagógico y su relación con la formación docente", "el trabajo diario del coordinador pedagógico" y "políticas públicas y el rol del coordinador pedagógico".

Palabras clave: coordinadora pedagógica; formación de profesores; estado del arte.

\section{INTRODUÇÃO}

${ }^{1} \mathrm{O}$ coordenador pedagógico $(\mathrm{CP})$ atualmente é figura central no processo de reconfiguração do ensino e da organização escolar. Este sujeito tem por papel ser o principal articulador, no ambiente escolar, entre famílias, professores, equipe gestora e demais profissionais pedagógicos e administrativos. De modo geral, o CP assume uma vasta gama de atribuições e funções dentro do processo de gestão da escola. Sendo assim, neste trabalho, buscando um olhar panorâmico sobre o que vem sendo produzido em nível maior (doutorado) na pós-graduação no Brasil sobre a figura do CP, produzimos um estudo do tipo "estado da arte", buscando perceber como tem sido realizada a caracterização destes sujeitos, a partir do Catálogo de Teses e dissertações (CTD) da Coordenação de Aperfeiçoamento de Pessoal de Nível Superior (CAPES). Sendo assim, pretendemos aqui responder a seguinte questão: como o CP vem sendo caracterizado em teses de doutorado presentes no CTD da CAPES?

Entendemos que realizar um trabalho do tipo "Estado da arte" permite contribuir para a sistematização de conhecimentos sobre determinado tema e/ou área específica, além de produzir interpretações diretas sobre esses conhecimentos. Nas palavras de Palacio, Granados e Villafáñez (2016, p. 07) o estado da arte contribui para:

Assim, o estado da arte permite o desenvolvimento de um pensamento claro e produtivo sobre um tema específico, no qual se assume analítica e interpretativamente os textos que acumulam conhecimentos para integrá-los coerentemente através da adoção da linguagem como instrumento de comunicação e meio fundamental para o desenvolvimento do pensamento. (Palacio, Granados e Villafáñez, 2016, p.07, tradução nossa)

Logo, nesta pesquisa, buscaremos realizar esforços interpretativos para demonstrar como o CP vem sendo caracterizado em teses de doutorado do CTD da CAPES, para que possamos "Ampliar o conhecimento sobre o que foi estudado, com o objetivo de construir argumentos que contribuam para justificar e definir o alcance de um estudo." (PALACIO, GRANADOS E VILLAFÁÑEZ, 2016, p.19, tradução nossa).

A escolha do CTD da CAPES ocorre pela importância deste repositório como principal registro de socialização de trabalhos em nível de pós-graduação no Brasil, abrangendo pesquisas de Mestrado e Doutorado, além de disponibilizar também ferramentas para refino de trabalhos por ano, área de conhecimento, tipo de pesquisa, instituição dentre outros. $\mathrm{Na}$ realização da presente pesquisa, utilizamos como descritor o termo 'coordenador pedagógico', utilizando as aspas para delimitar melhor o conceito trabalhado (do contrário buscaria individualmente as palavras coordenador e pedagógico). A pesquisa resultou em 62 produções e refinamos apenas na área de conhecimento educação. Também selecionamos apenas teses de doutorado por entender que este

\footnotetext{
${ }^{1}$ O presente trabalho foi realizado com apoio da Coordenação de Aperfeiçoamento de Pessoal de Nível Superior -
} Brasil (CAPES) Código de Financiamento 001. 
é o maior nível de pós-graduação e que, por este motivo, encontraríamos maior relevância nos trabalhos. Com o refinamento dos resultados, chegamos a 45 trabalhos localizados.

Realizamos a leitura dos resumos destas 45 produções e, descartamos 27 por fugir da temática. Além disso, 4 trabalhos não foram autorizados sua publicação pelos autores. Com isso, realizamos a leitura em ordem cronológica e posterior análise a partir de 14 produções, a saber:

Tabela 01: caracterização dos trabalhos localizados no CTD da CAPES

\begin{tabular}{|c|c|c|}
\hline Título & Autor & Ano \\
\hline $\begin{array}{l}\text { Os saberes das relações interpessoais e a formação inicial do } \\
\text { coordenador pedagógico }\end{array}$ & $\begin{array}{l}\text { Eliane Bambini } \\
\text { Gorgueira Bruno }\end{array}$ & 2006 \\
\hline $\begin{array}{l}\text { Formação continuada para coordenadores pedagógicos: e a escola, } \\
\text { como fica? }\end{array}$ & Marilene Garcia & 2008 \\
\hline $\begin{array}{l}\text { O coordenador pedagógico e o desafio da formação contínua do } \\
\text { docente na escola }\end{array}$ & Isaneide Domingues & 2009 \\
\hline $\begin{array}{l}\text { A tecitura da ação do coordenador pedagógico da EJA: saberes } \\
\text { necessários à medição do trabalho docente em alfabetização }\end{array}$ & $\begin{array}{l}\text { Edneide da conceição } \\
\text { Bezerra }\end{array}$ & 2009 \\
\hline $\begin{array}{l}\text { A atuação da coordenação pedagógica em conjunto com os } \\
\text { professores no processo de recontextualização da política oficial no } \\
1^{\circ} \text { ano do Ensino Fundamental no Município do Rio de Janeiro }\end{array}$ & $\begin{array}{l}\text { Vânia Finholdt Ângelo } \\
\text { Leite }\end{array}$ & 2012 \\
\hline $\begin{array}{l}\text { Um estudo sobre a formação continuada do coordenador } \\
\text { pedagógico desenvolvida pelo CEFAPRO de Cáceres.MT }\end{array}$ & Rinalda Bezerra Carlos & 2013 \\
\hline $\begin{array}{l}\text { O professor especialista iniciante: contribuições do coordenador } \\
\text { pedagógico para seu trabalho }\end{array}$ & $\begin{array}{l}\text { Andrea Jamil Paiva } \\
\text { Mollica }\end{array}$ & 2014 \\
\hline $\begin{array}{c}\text { Ser "o faz-tudo" na escola: a dimensão subjetiva do trabalho do } \\
\text { coordenador pedagógico }\end{array}$ & $\begin{array}{l}\text { Cristiane de Sousa } \\
\text { Moura Teixeira }\end{array}$ & 2014 \\
\hline $\begin{array}{c}\text { Os coordenadores pedagógicos de escolas da Secretaria Municipal de } \\
\text { Educação da Cidade do Rio de Janeiro como mediadores das } \\
\text { políticas curriculares }\end{array}$ & $\begin{array}{l}\text { Jane Cordeiro de } \\
\text { Oliveira }\end{array}$ & 2015 \\
\hline $\begin{array}{l}\text { O cotidiano do coordenador pedagógico na visão da complexidade: } \\
\text { práticas de formação continuada no cenário da educação infantil }\end{array}$ & $\begin{array}{c}\text { Barbara Raquel do } \\
\text { Prado Gimenez Corrêa }\end{array}$ & 2016 \\
\hline $\begin{array}{l}\text { Escola de tempo integral e os meandros da coordenação pedagógica } \\
\text { no município de Campo Grande - MS }\end{array}$ & Katyuscia Oshiro & 2017 \\
\hline $\begin{array}{c}\text { O trabalho do coordenador pedagógico e a formação continuada de } \\
\text { professores centrada na escola inclusiva em Belém-PA. }\end{array}$ & Míriam Matos Amaral & 2019 \\
\hline $\begin{array}{c}\text { A mediação do coordenador pedagógico no desenvolvimento } \\
\text { profissional de professores que ensinam matemática }\end{array}$ & $\begin{array}{l}\text { Juliane do Nascimento } \\
\text { Mosquini }\end{array}$ & 2019 \\
\hline $\begin{array}{l}\text { O programa escola de gestores da educação básica e a política de } \\
\text { formação continuada para coordenadores pedagógicos: que } \\
\text { coordenação pedagógica? }\end{array}$ & $\begin{array}{l}\text { Maria Cristina Moraes } \\
\text { de Carvalho }\end{array}$ & 2020 \\
\hline
\end{tabular}

Fonte: Elaborado pelos autores.

Como forma de auxílio para realização das análises e da descrição das pesquisas localizadas, separamos os trabalhos em categorias. Segundo Gomes (2004),

A palavra categoria, em geral, se refere a um conceito que abrange elementos ou aspectos com características comuns ou que se relacionam entre si. Essa palavra está ligada à ideia de classe ou série. (GOMES, 2004, p.70).

Pretendemos assim produzir reflexões sobre a figura do CP, partindo das categorias para a individualidade do trabalho. Dessa forma, produzimos 3 categorias: 1 - coordenador pedagógico e 
sua relação com a formação docente (6 pesquisas); 2- o trabalho cotidiano do coordenador pedagógico (4 pesquisas); 3- políticas públicas e atuação do coordenador pedagógico (4 pesquisas). $\mathrm{Na}$ continuidade deste trabalho, realizaremos uma rápida apresentação das categorias e uma síntese das pesquisas, enfocando principalmente nos resultados que rementem à figura do CP.

Tabela 02: Categorias e pesquisas relacionadas

\begin{tabular}{|c|c|}
\hline Categorias & Trabalhos \\
\hline & Bruno (2006) \\
O coordenador pedagógico e sua relação com a formação & Garcia (2008) \\
docente & Domingues (2009) \\
& Carlos (2013) \\
& Corrêa (2016) \\
& Amaral (2019) \\
\hline O trabalho cotidiano do coordenador pedagógico & Bezerra (2009) \\
& Mollica (2014) \\
Políticas públicas e atuação do coordenador pedagógico & Tosquini (2019) \\
\hline & Leite (2012) \\
& Oliveira (2015) \\
& Oshiro (2017) \\
\hline
\end{tabular}

Fonte: Elaborado pelo autor.

\section{O COORDENADOR PEDAGÓGICO E SUA RELAÇÃO COM A FORMAÇÃO DOCENTE}

Segundo Garrido (2007) o trabalho do CP é, principalmente, auxiliar na formação docente em serviço, ou seja, no centrada no próprio local de trabalho. A formação docente em espaços escolares tem o desafio de afastar-se das práticas tradicionais de depósitos informativos através de palestras e/ou cursos que mantém os professores sempre passivos e imóveis frente aos desafios da atuação docente. Se tomarmos as ideias de Freire e Shor (2013) as práticas de formação docente tem o desafio de perceber as salas de aulas como lugar de libertação e de experimentação, não somente pelos alunos, mas também pelos professores. Ainda que possa ser extremamente difícil, visto que não existe "plano perfeito" a ser seguido para que se possa realizar uma formação reflexiva e transformadora a partir do ambiente escolar, o CP é o profissional que, a partir de sua compreensão da realidade e das relações construídas no ambiente escolar, propõem possibilidades formativas singulares para os docentes de sua instituição. Sendo assim, esta categoria se mostra de extrema importância para a compreensão do CP como ator central na busca por percursos formativos docentes.

Iniciando pelo trabalho de Bruno (2006), que buscou em linhas gerais compreender como se desenvolve a produção de saberes docentes pelos CPs, no que tange às relações interpessoais no ambiente escolar. Para tanto, foram entrevistados 282 alunos e 18 professores, provenientes de cursos de pedagogia de 12 instituições de ensino superior do estado de São Paulo. Para tanto, a pesquisadora se utilizou de questionários e de dois encontros focais para a produção dos dados.

Como principais resultados, a autora apontou que ainda não é possível identificar nos cursos de licenciatura em pedagogia disciplinas que abordem diretamente o trabalho do CP, apesar 
de alguns conhecimentos serem abordados na parte da gestão escolar. Também é apontado que os saberes que tangem as relações interpessoais ainda não estão sistematizados nos currículos de formação e dependem da subjetividade de cada sujeito para se desenvolverem.

Outrossim, o trabalho de Garcia (2008) intentou perceber se os conhecimentos desenvolvidos em cursos de formação continuada providos pela rede municipal de São Paulo/SP, efetivamente chegavam a ser utilizados pelas instituições escolares, como eram utilizados e se eram compartilhados entre os diferentes sujeitos. Para isso, a autora utilizou-se de entrevistas individuais e entrevistas recorrentes com 4 profissionais que ocupam o cargo de $\mathrm{CP}$ em escolas da rede pública municipal da referida cidade. Foram selecionadas duas escolas com altos indicadores de desempenho e 2 escolas com baixos indicadores de desempenho.

Como principais achados de pesquisa, foi apontado que os cursos de formação continuada construíram junto aos CPs conhecimentos que foram parcialmente compartilhados nas escolas, principalmente pela falta de acompanhamento da administração, as ações formativas desenvolvidas em demasia e sem levar em consideração as reais necessidades profissionais desses sujeitos.

Ainda, a pesquisa de Domingues (2009) procurou compreender como os CPs realizam e organizam a formação continuada centrada no ambiente escolar, a partir da autonomia do próprio coletivo docente. A pesquisadora realizou o estudo com quatro CPs, envolvendo duas escolas e dois grupos de professores, envolvidos em um projeto formativo da rede municipal de São Paulo/SP, denominado Jornada Especial Integral de formação. Para a produção de dados, foram utilizadas entrevistas semiestruturadas e organizados grupos dialogais em dois encontros com grupos de docentes participantes do referido projeto.

Entre os principais resultados da pesquisa, foi possível compreender a fragilidade da formação inicial e da formação continuada voltada para os CPs, e por este motivo, os profissionais que atuam nesta função desenvolvem saberes, saberes-fazer próprios a partir da subjetividade de cada sujeito. Ainda, é posto que, utilizando-se da sua autonomia, esses profissionais investem em projetos coletivos calcados no protagonismo docente e no enfrentamento à cultura imposta pelo sistema. Por fim, os CPs se reconhecem como profissionais responsáveis pela formação no ambiente escolar, mas também se percebem como sujeitos em constante processo de aprendizagem e reflexão sobre sua prática.

Na sequência, o trabalho de Carlos (2013) procurou compreender se o Centro de Formação e Atualização de Profissionais da Educação Básica (CEFAPRO) apresentou possibilidades formativas para o desenvolvimento da identidade e da atuação profissional dos CPs. A pesquisa teve como pano de fundo um projeto para formação de gestores e assessores escolares do munícipio das cidades de Cáceres e Mirassol D’oestes/MT. A pesquisa contou com entrevistas, do tipo semiestruturadas, realizadas com 20 CPs, 5 diretores escolares e 4 professores formadores do CEFAPRO. Ainda, foram utilizados questionários respondidos por 59 professores e 10 funcionários (não-docentes).

A partir dos dados obtidos, a pesquisadora apontou que os CPs são formados pelo CEFAPRO para a resolução de demandas e problemas urgentes no ambiente escolar. Porém, as competências necessárias estritamente para a formação do CP, não são levadas em consideração. Ainda, as formações não levam em consideração as experiências e a construção da identidade profissional dos CPs.

Também, o trabalho de Corrêa (2016) buscou, à luz da epistemologia do pensamento complexo, analisar e refletir sobre a atuação do CP em ações de formação docente, visando o trabalho com a educação infantil. Esta pesquisa, do tipo estudo de caso, realizou a produção de dados por meio de observação participativa em momentos formativos do Núcleo Regional de Educação de Curitiba/PR e entrevistas episódicas com 7 profissionais da rede municipal de 
educação de Curitiba, que atuavam como Suporte Técnico Pedagógico em Núcleos Regionais de Educação.

Nos resultados da pesquisa, evidenciou-se a posição do CP como "formador de formadores". Também foi possível compreender a importância da formação continuada para a melhoria da educação. Além disso, o CP através da construção de sua identidade profissional qualifica sua atuação, através de práticas de formação.

Por fim, o trabalho de Amaral (2019) objetivou analisar o trabalho do CP, a partir de práticas formativas, tendo como horizonte de pesquisa uma escola inclusiva. Esta pesquisa, do tipo qualitativa, foi realizada a partir de duas escolas da rede escolar municipal de Belém/PA, em entrevistas com 14 profissionais atuantes destas escolas, sendo: 7 CPs, 5 docentes e 2 educadores especiais.

Nos principais achados da pesquisa, foi percebido que as condições físicas e pedagógicas precárias das escolas, influenciavam diretamente o trabalho do CP. Também, o CP conta com pouca autonomia para realização de seu trabalho, além de serem pouco reconhecidos, sobretudo no trabalho com escolar inclusivo.

Tabela 03: Ideias-chave da categoria "O coordenador pedagógico e sua relação com a formação docente"

\begin{tabular}{|c|c|}
\hline \multicolumn{2}{|c|}{$\begin{array}{l}\text { O COORDENADOR PEDAGÓGICO E SUA RELAÇÃO COM A FORMAÇÃO } \\
\text { DOCENTE }\end{array}$} \\
\hline Bruno (2006) & $\begin{array}{l}\text { - Não existem disciplinas que abordem diretamente a função do CP. } \\
\text { - Os saberes interpessoais são desenvolvidos na subjetividade de cada } \\
\text { sujeito. } \\
\text { - Não é possível identificar nos cursos de formação inicial o } \\
\text { desenvolvimento de saberes interpessoais. }\end{array}$ \\
\hline Garcia (2008) & $\begin{array}{l}\text { - Os saberes construídos em cursos de formação continuada nem } \\
\text { sempre são compartilhados entre os sujeitos. } \\
\text { - A administração pública escolar e municipal não realizam } \\
\text { acompanhamento das formações. } \\
\text { - Formações realizadas em demasia atrapalham o desenvolvimento } \\
\text { profissional dos CPs, além de não levar em consideração a real } \\
\text { necessidade profissional desses sujeitos. }\end{array}$ \\
\hline Domingues (2009) & $\begin{array}{l}\text { - A formação inicial e continuada do CP apresenta fragilidades. } \\
\text { - Os CPs constroem saberes-fazer próprios a partir de sua própria } \\
\text { experiência profissional. } \\
\text {-Valendo-se de sua autonomia, os CPs se utilizam de projetos de } \\
\text { formação coletivos baseados no protagonismo docente. } \\
\text { - Os CPs se reconhecem que são os responsáveis pela formação docente } \\
\text { na escola. } \\
\text { - Os CPs se percebem como sujeitos aprendentes, a partir de sua reflexão } \\
\text { crítica. }\end{array}$ \\
\hline Carlos (2013) & $\begin{array}{l}\text { - CPs são formados para resolver problemas urgentes. } \\
\text { • Os saberes e competências não são desenvolvidos levando em conta a } \\
\text { atuação do CP. }\end{array}$ \\
\hline
\end{tabular}


DOI: $10.12957 /$ teias.2022.61091

\begin{tabular}{|c|c|}
\hline & $\begin{array}{l}\text { - As formações destinadas aos CPs não auxiliam o desenvolvimento da } \\
\text { identidade profissional e nem levam em consideração suas experiências. }\end{array}$ \\
\hline Corrêa (2016) & $\begin{array}{l}\text {-CP assume o papel de "formador de formadores". } \\
\text { - Formação continuada do CP contribui para o desenvolvimento de } \\
\text { processos educativos melhores. } \\
\text {-Através da formação continuada, os CPs constroem sua identidade } \\
\text { profissional e qualificam suas práticas. }\end{array}$ \\
\hline Amaral (2019) & $\begin{array}{l}\text { - As condições físicas e pedagógicas precárias atrapalham a atuação do } \\
\mathrm{CP} \text {. } \\
\text { - CP conta com pouca autonomia para realizar seu trabalho. } \\
\text { - O reconhecimento da importância do CP pedagógico é escasso, } \\
\text { sobretudo na educação inclusiva. }\end{array}$ \\
\hline \multicolumn{2}{|c|}{$\begin{array}{l}\text { Síntese geral da categoria - Além de na formação inicial não ser abordada diretamente os } \\
\text { saberes utilizados na atuação do CP, como por exemplo os saberes interpessoais que são } \\
\text { desenvolvidos a partir das experiências de cada sujeito, a formação continuada também } \\
\text { apresenta fragilidades, uma vez que os saberes nem sempre são compartilhados entre os } \\
\text { sujeitos e as administrações não levam em conta o interesse e a necessidade dos CPs para o } \\
\text { planejamento de formações. Também, as condições administrativas, físicas e pedagógicas } \\
\text { precárias dificultam o trabalho do CP, bem como o reconhecimento escasso da importância } \\
\text { deste profissional, que não tem formações voltadas para sua atuação e nem apoiadas em sua } \\
\text { experiência. Porém, ao assumir o papel de "formador de formadores" e construir seus próprios } \\
\text { saberes a partir de sua atuação, se utilizando de sua condição de aprendentes, sua reflexão } \\
\text { crítica e sua autonomia os CPs percebem o desafio de conduzir a formação docente na escola, } \\
\text { além de resolver questões urgentes na gestão pedagógica, o que irá contribuir para o } \\
\text { desenvolvimento de processos educativos melhores e para a sua construção da identidade } \\
\text { profissional, o que irá qualificar suas práticas. }\end{array}$} \\
\hline
\end{tabular}

Fonte: Elaborado pelos autores.

\section{O TRABALHO COTIDIANO DO COORDENADOR PEDAGÓGICO}

Historicamente, as escolas são reflexo do que se passa na sociedade. O espaço escolar não passa incólume ao que se passa fora dele. Freire (2001) contribuiu para essa ideia ao afirmar que:

É que os conflitos sociais, o jogo de interesses, as contradições que se dão no corpo da sociedade se refletem necessariamente no espaço das escolas. E não podia deixar de ser assim. As escolas e a prática educativa que nelas se dá não poderiam estar imunes ao que se passa nas ruas do mundo. (FREIRE, 2001, p. 49)

Em um mundo extremamente complexo e dinâmico, o ambiente escolar não poderia ser diferente. As respostas para desafios do mundo, precisam ser rápidas e assertivas, principalmente por gestores públicos e/ou responsáveis por coordenar ações e serviços à comunidade. No caso da escola, os CPs encontram-se diariamente envoltos neste processo. Sua atuação na rotina escolar, para além da formação, segundo Placco, Almeida e Souza (2011) também está baseada nas relações entre alunos e professores e entre professores e famílias, atuando em um amplo espectro de possibilidades, indo desde questões curriculares, perpassando por projetos institucionais da escola, chegando à resolução de conflitos e resolução de problemas cotidianos. Frente a esta ampla gama 
de funções, esta categoria aqui apresenta os trabalhos que discutem diretamente as funções e a atuação cotidiana do CP.

Partindo do trabalho de Bezerra (2009), que buscou pesquisar os saberes utilizados pelos CPs, na atuação junto à professores alfabetizadores da educação de jovens e adultos (EJA). Para isso, a autora se valeu de pesquisa qualitativa, do tipo estudo de caso, tendo como lócus de pesquisa o EJA de uma escola periférica municipal de Natal/RN. Como aportes metodológicos, foram utilizadas a observação participante, durante um ano, em diversos momentos da rotina da instituição escolar. Também foram utilizados caderno de campo, questionário e entrevistas semiestruturadas em 4 professoras que atuam na função de CP.

Como principais achados, a pesquisa evidenciou que o trabalho do CP é desenvolvido em comunhão com professores e outros profissionais da escola e que as diversas tarefas que se entrecruzam no dia a dia do CP atrapalham a mediação do trabalho com os docentes. Ainda, a pesquisa apreendeu o fato de os saberes construídos na prática diária serem de extrema importância para o desenvolvimento das ações dos CPs.

Outrossim, o trabalho de Molica (2014), buscou entender que ações o CP pode desenvolver no apoio ao docente especialista na atribuição de suas ações de ensino. A pesquisa realizada foi qualitativa e utilizou-se de entrevistas semiestruturadas, realizadas com 3 docentes iniciantes, sendo dois da rede municipal e um da rede estadual de ensino e 2 CPs, sendo um da rede municipal e outro da rede estadual de ensino da cidade de São Paulo/SP.

Nos achados da pesquisa, no que tange à figura do CP, a autora ressaltou que este profissional promove a articulação entre professores mais experientes com os menos experientes e auxiliar na integração entre todos os docentes. Ainda, o CP atua na apresentação do contexto escolar, trazendo informações para os docentes durante o período do ano de trabalho.

Ainda, Teixeira (2014) buscou estudar o que significa, para os CPs, sua atuação em seu ambiente de trabalho. O lócus de pesquisa é a rede pública estadual de Teresina/PI, onde foram aplicados questionários e realizadas entrevistas individuais e coletivas reflexivas com 3 CPs que atuam em escolas da rede supracitada.

Em suas considerações finais, a pesquisadora evidenciou que as significações construídas pelos CPs apontam para a visão de um "faz tudo" na escola, que ora atua na formação continuada, ora no desenvolvimento profissional docente, além de sujeitos que evidenciam a extensa quantidade de ações simultâneas nas escolas públicas. Por fim, também foi ressaltado que a visão do CP como "faz tudo" está intimamente relacionada à sua motivação e seus sentimentos em trabalhar com escolas públicas, o que produz um potencial formativo nos próprios sujeitos.

Por fim, a pesquisa de Mosquini (2019) intentou investigar a atuação dos CPs na mediação entre docentes, em momentos de formação continuada, de professores que ensinam matemática para os anos iniciais do ensino fundamental. A pesquisa foi realizada em uma escola da rede pública municipal de Pompeia/SP. A pesquisa do tipo qualitativa, do tipo pesquisa-intervenção inspirada também na pesquisa-formação, realizada a partir de reuniões do tipo grupo de estudo, acompanhamento dos docentes, e produção coletiva de aulas.

Como principais resultados da pesquisa, destacamos que os docentes, a partir da interação com os CPs perceberam ser possível reconfigurar sua atuação na escola. Ainda, a escola foi percebida como espaço de produção e reconstrução de conhecimentos, que são desenvolvidos em espaços coletivos. Por fim, o CP na mediação das relações na escola possibilita a reflexão crítica sobre a prática, problematizando-a e propondo novas formas de aprender em conjunto. 
DOI: $10.12957 /$ teias.2022.61091

Tabela 04: Ideias-chave da categoria "O trabalho cotidiano do coordenador pedagógico"

\begin{tabular}{|c|c|}
\hline \multicolumn{2}{|c|}{ O TRABALHO COTIDIANO DO COORDENADOR PEDAGÓGICO } \\
\hline Bezerra (2009) & $\begin{array}{l}\text { - O trabalho do CP é realizado em conjunto com os outros profissionais } \\
\text { da escola. } \\
\text { - A multiplicidade de tarefas atrapalha a mediação com os docentes. } \\
\text { - Os saberes construídos pelos CPs na prática diária são extremamente } \\
\text { importantes para a sua boa atuação. }\end{array}$ \\
\hline Molica (2014) & $\begin{array}{l}\text { - O CP promove a articulação entre professores mais experientes com os } \\
\text { menos experientes. } \\
\text { - O CP atua para integrar todos os docentes no ambiente escolar. } \\
\text { - A apresentação do contexto escolar é realizada pelo CP que também traz } \\
\text { informações novas para os docentes durante sua prática. }\end{array}$ \\
\hline Teixeira (2014) & $\begin{array}{l}\text { - O CP como sujeito que "faz-tudo". } \\
\text {-A diversidade de ações atrapalha o trabalho do CP. } \\
\text { •A motivação e os sentimentos pela escola balizam o trabalho do CP. }\end{array}$ \\
\hline Mosquini (2019) & $\begin{array}{l}\text { - A interação entre docentes e CP reconfigura a atuação de ambos na } \\
\text { escola. } \\
\text { - O CP atuando como mediador nas relações entre docentes possibilita a } \\
\text { produção e reconstrução de novos conhecimentos. } \\
\text { - A atuação do CP auxilia na problematização e na reflexão sobre a prática, } \\
\text { possibilitando aos docentes aprender em conjunto. }\end{array}$ \\
\hline $\begin{array}{l}\text { Síntese geral da c } \\
\text { mediando e articul } \\
\text { entre si e com a rea } \\
\text { produção de conhe } \\
\text { sobre a prática e da } \\
\text { "faz-tudo" que, pe }\end{array}$ & $\begin{array}{l}\text { egoria - A atuação do CP é marcada pelo trabalho em conjunto, } \\
\text { do as relações entre os diversos profissionais da escola, integrando-os } \\
\text { dade escolar, possibilitando a reorganização da atuação docente e a } \\
\text { mentos no âmbito escolar pela prática diária, através da reflexão constante } \\
\text { notivação dos profissionais. Porém, os CPs ainda são vistos como sujeitos } \\
\text { sua multiplicidade de funções tem seu trabalho dificultado. }\end{array}$ \\
\hline
\end{tabular}

Fonte: Elaborado pelos autores.

\section{POLÍTICAS PÚBLICAS E A ATUUAÇÃO DO COORDENADOR PEDAGÓGICO}

A figura do CP surge no contexto educacional brasileiro, a partir da redemocratização de 1988, em contraposição à tarefa de supervisor escolar anteriormente utilizada, conforme demonstrado por Carvalho (2020). Atualmente, a figura do CP é permeada pela multiplicidade de funções. Segundo dados de Placco, Almeida e Souza (2011), os desvios de função são comuns na figura do CP:

O que aparece claramente, neste estudo, são algumas ações que revelam os CPs muito envolvidos no atendimento a pessoas ou substituindo professores. Alguns CPs (38\%) consideram excessivo esse tempo que passam substituindo professores e, dos $50 \%$ dos CPs que atendem pais ao telefone todos os dias, $70 \%$ consideram essa dedicação adequada. Apenas $26 \%$ consideram insufciente o tempo dedicado ao Projeto Político-Pedagógico (PPP) da escola (PLACCO, ALMEIDA E SOUZA, 2011, p. 238) 
Esse panorama somente será mudado, quando a cultura escolar mudar. Isso, porém, acontecerá somente quando induzido por políticas públicas que valorizem o CP e delimitem sua atuação visando qualificá-la. Posto isso, esta categoria se mostra importante para compreender o que vem sendo produzido a partir de trabalhos que envolvam políticas públicas e a figura do CP.

Iniciando pelo trabalho de Leite (2012) que, entendendo os CPs como coprodutores das políticas educativas de recontextualização da língua portuguesa na rede municipal da cidade do Rio de Janeiro/RJ, buscou analisar a atuação desses sujeitos. O trabalho foi realizado em duas escolas, da zona oeste da cidade supracitada. As escolas foram selecionadas a partir do bom desempenho no Índice de Desenvolvimento da Educação Básica (IDEB) e pelo tempo de manutenção dos CPs no cargo (mais de 5 anos). Esta pesquisa, de cunho de qualitativo, utilizou-se de observações participantes de conselhos de classe e de aulas, entrevistas semiestruturadas com 4 sujeitos que atuam na função de CP.

Como principais achados, esta pesquisa apontou que os CPs ao passo que garantiam um processo de ensino-aprendizagem para seus alunos, também buscavam cumprir determinações da Secretaria Municipal de Educação (SME). Os CPs orientavam os professores sobre o como ensinar, se mantendo entre a proposta da escola e a proposta da SME, respeitando o tempo dos alunos e aos conteúdos propostos pelas políticas curriculares.

Ainda, a pesquisa de Oliveira (2015) intentou compreender como o CP realiza a "mediação política" entre as políticas propostas pela SME do Rio de Janeiro/RJ e a comunidade escolar. A pesquisa do tipo qualitativa, entrevistou 18 CPs de escolas com bom desempenho no IDEB, do município do rio de janeiro, a partir de um roteiro semiestruturado.

À guisa de conclusões, a pesquisadora apontou que os CPs se enxergam como "bombeiros" que atuam em situações emergenciais para responder as demandas. A mediação política é realizada nos momentos de planejamento, em que os professores recebem dos CPs as informações provenientes da SME e sanam as dúvidas sobre as políticas e projetos adotados.

Ainda, o trabalho de Oshiro (2017) busca investigar a partir da atuação do CP as estratégias de formação em trabalho, durante reuniões de planejamento coletivo. A pesquisa foi realizada no contexto de uma escola pública municipal de tempo integral do município de Campo Grande/RS. O estudo, de cunho qualitativo utilizou-se de questionários e entrevistas semiestruturadas com 25 profissionais atuantes na referida escola por no mínimo 2 anos, sendo 19 docentes, 4 CPs e dois diretores.

Nos principais resultados da pesquisa, foi demonstrado que o CP atua como "parceiro" do professor nas suas ações cotidianas e em suas ações formativas. A extensa gama de atribuições do CP foi apontada como um grande desafio para o desenvolvimento de ações mais qualificadas na escola, além de ser imperativa mudanças na organização escolar para que esses sujeitos possam atuar mais incisivamente na formação docente na escola.

Por fim, o trabalho de Carvalho (2020) buscou pesquisar de que forma a formação política do CP se desenvolve a partir do Programa Nacional Escola de Gestores da Educação Básica Pública (PNEGEBP), mais especificamente em um curso de especialização lato sensu, desenvolvido na Universidade Federal de Ouro Preto (UFOP) - MG. A pesquisadora entrevistou a consultora do Ministério da Educação responsável pela formulação do PNEGEBP, a coordenadora da especialização na UFOP, 4 professores do curso, sem vínculo profissional com a UFOP, selecionados via edital público, e uma professora responsável pela construção das disciplinas, professora da UFOP. Todos esses sujeitos foram entrevistados utilizando um roteiro semiestruturado. 
Nos resultados da pesquisa, o PNEGEBP através de sua política formativa demonstra o papel do CP como organizador do trabalho articulado na escola, considerando a dimensão política de sua função. Além disso, se percebe uma grande demanda pela formação inicial e continuada dos CPs.

Tabela 05: Ideias-chave da categoria "Políticas públicas e a atuação do coordenador pedagógico"

\begin{tabular}{|c|c|}
\hline \multicolumn{2}{|c|}{ POLÍTICAS PÚBLICAS E A ATUAÇÃO DO COORDENADOR PEDAGÓGICO } \\
\hline Leite (2012) & $\begin{array}{l}\text { Os CPs visam garantir um bom processo de ensino-aprendizagem para } \\
\text { seus alunos. } \\
\text { A atuação dos CPs se mantinham entre as determinações próprias da } \\
\text { escola e as da SME. } \\
\text { Os professores eram orientados pelos CPs, quanto às políticas curriculares } \\
\text { e o tempo de aprendizagem de cada um. }\end{array}$ \\
\hline Oliveira (2015) & $\begin{array}{l}\text { - CPs se enxergam como bombeiros, atuando em situações emergenciais. } \\
\text { - Os professores sanam suas dúvidas sobre as políticas e projetos } \\
\text { escolares com os CPs em seus momentos de planejamento. } \\
\text { - Os CPs realizam a mediação política realizando os repasses de } \\
\text { informações entre a SME e os professores. }\end{array}$ \\
\hline Oshiro (2017) & $\begin{array}{l}\text { - O CP é visto como "parceiro” do professor em sua rotina diária e para } \\
\text { auxiliar sua formação. } \\
\text {-As diversas ações do CP atrapalham seu trabalho na escola. } \\
\text {-São necessárias mudanças para que os CPs possam qualificar sua atuação } \\
\text { formativa com os docentes. }\end{array}$ \\
\hline Carvalho (2020) & $\begin{array}{l}\text { - O CP é visto como organizador e articulador do trabalho pedagógico na } \\
\text { escola. } \\
\text { - Foi percebida uma grande demanda pela formação inicial e continuada } \\
\text { do CP na escola. }\end{array}$ \\
\hline $\begin{array}{l}\text { Síntese geral da c } \\
\text { educação de qualid } \\
\text { organizando o trab } \\
\text { em suas demandas } \\
\text { SMEs, além de reg } \\
\text { em um único sujeit } \\
\text { observada a deman }\end{array}$ & $\begin{array}{l}\text { tegoria - A partir de seu trabalho, os CPs buscavam garantir uma } \\
\text { de para os alunos, atuando em situações emergenciais, articulando e } \\
\text { ho docente, se mostrando sempre à disposição para auxiliar o professor } \\
\text { para repassar informações importantes, seguindo determinações das } \\
\text { s próprias das escolas. Porém, o grande desafio é conciliar tantas funções } \\
\text { o que atrapalha o desenvolvimento de ações, principalmente quando } \\
\text { a pela formação inicial e continuada dos CPs. }\end{array}$ \\
\hline
\end{tabular}

Fonte: Elaborado pelos autores.

\section{POLÍTICAS PÚBLICAS E A ATUACCÃO DO COORDENADOR PEDAGÓGICO}

A partir da leitura das 14 pesquisas que tangem a figura e a atuação do $\mathrm{CP}$, foi possível depreender como está sendo caracterizado esses sujeitos, a partir de pesquisas que enfocam seu trabalho. Dessa forma, depois de realizadas as sínteses necessárias a partir das considerações apontadas pela pesquisa e de organizar as ideias postas nestes trabalhos, entendemos que é imprescindível sintetizar, a partir das categorias, uma ideia de síntese geral para este estado da arte. 
DOI: $10.12957 /$ teias.2022.61091

Tabela 06: Síntese geral da caracterização do Coordenador pedagógico

\begin{tabular}{|c|c|}
\hline CATEGORIA & SÍNTESE GERAL \\
\hline $\begin{array}{l}\text { O coordenador pedagógico e sua relação } \\
\text { com a formação docente }\end{array}$ & $\begin{array}{l}\text { Além de na formação inicial não ser abordada } \\
\text { diretamente os saberes utilizados na atuação do CP, } \\
\text { como por exemplo os saberes interpessoais que são } \\
\text { desenvolvidos a partir das experiências de cada } \\
\text { sujeito, a formação continuada também apresenta } \\
\text { fragilidades, uma vez que os saberes nem sempre são } \\
\text { compartilhados entre os sujeitos e as administrações } \\
\text { não levam em conta o interesse e a necessidade dos } \\
\text { CPs para o planejamento de formações. Também, as } \\
\text { condições administrativas, físicas e pedagógicas } \\
\text { precárias dificultam o trabalho do CP, bem como o } \\
\text { reconhecimento escasso da importância deste } \\
\text { profissional, que não tem formações voltadas para } \\
\text { sua atuação e nem apoiadas em sua experiência. } \\
\text { Porém, ao assumir o papel de "formador de } \\
\text { formadores" e construir seus próprios saberes a } \\
\text { partir de sua atuação, se utilizando de sua condição } \\
\text { de aprendentes, sua reflexão crítica e sua autonomia } \\
\text { os CPs percebem o desafio de conduzir a formação } \\
\text { docente na escola, além de resolver questões } \\
\text { urgentes na gestão pedagógica, o que irá contribuir } \\
\text { para o desenvolvimento de processos educativos } \\
\text { melhores e para a sua construção da identidade } \\
\text { profissional, o que irá qualificar suas práticas. }\end{array}$ \\
\hline $\begin{array}{l}\text { O trabalho cotidiano do coordenador } \\
\text { pedagógico }\end{array}$ & $\begin{array}{l}\text { A atuação do CP é marcada pelo trabalho em } \\
\text { conjunto, mediando e articulando as relações entre } \\
\text { os diversos profissionais da escola, integrando-os } \\
\text { entre si e com a realidade escolar, possibilitando a } \\
\text { reorganização da atuação docente e a produção de } \\
\text { conhecimentos no âmbito escolar pela prática diária, } \\
\text { através da reflexão constante sobre a prática e da } \\
\text { motivação dos profissionais. Porém, os CPs ainda } \\
\text { são vistos como sujeitos "faz-tudo" que, pela sua } \\
\text { multiplicidade de funções tem seu trabalho } \\
\text { dificultado. }\end{array}$ \\
\hline $\begin{array}{l}\text { Políticas públicas e atuação do } \\
\text { coordenador pedagógico }\end{array}$ & $\begin{array}{l}\text { A partir de seu trabalho, os CPs buscavam garantir } \\
\text { uma educação de qualidade para os alunos, atuando } \\
\text { em situações emergenciais, articulando e } \\
\text { organizando o trabalho docente, se mostrando } \\
\text { sempre à disposição para auxiliar o professor em } \\
\text { suas demandas e para repassar informações } \\
\text { importantes, seguindo determinações das SMEs, } \\
\text { além de regras próprias das escolas. Porém, o grande } \\
\text { desafio é conciliar tantas funções em um único }\end{array}$ \\
\hline
\end{tabular}




\begin{tabular}{|l|l|}
\hline & $\begin{array}{l}\text { sujeito, o que atrapalha o desenvolvimento de ações, } \\
\text { principalmente quando observada a demanda pela } \\
\text { formação inicial e continuada dos CPs. }\end{array}$ \\
\hline SÍNTESE GERAL DO ESTADO DA ARTE. \\
\hline $\begin{array}{l}\text { Por mais que existam desafios para a qualificação do trabalho dos CPs, como ausência de } \\
\text { formação inicial e continuada de qualidade e focada nas reais necessidades dos sujeitos, uma } \\
\text { atuação ampla, com gama de atividades extremamente grande, com desvios de funções em } \\
\text { condições físicas, administrativas e pedagógicas precárias, os CPs tem contornado esses } \\
\text { problemas. Acima de tudo, esses sujeitos se valem do trabalho coletivo, que integra os diversos } \\
\text { atores da comunidade escolar, da reflexão crítica sobre a sua prática, da motivação por uma } \\
\text { educação de qualidade para atuar e, enquanto atua, produzir saberes que são utilizados em seu } \\
\text { cotidiano, reconhecendo a realidade escolar e trabalhando com professores, demais membros da } \\
\text { equipe pedagógica e da comunidade escolar para melhorar as práticas formativas e auxiliar os } \\
\text { professores a qualificar sua prática pedagógica. }\end{array}$ \\
\hline
\end{tabular}

Fonte: Elaborado pelos autores.

Diante disso, é razoável que se perceba que o trabalho do CP ainda não tem limites visíveis quanto à sua atuação. Isso se torna um desafio, ao passo que as condições de trabalho (físicas, politicas, pedagógicas e administrativas) não são as melhores. Ainda assim, a partir do reconhecimento próprio da importância de seu papel na formação continuada centrada na escola e no compromisso com uma educação de qualidade para os alunos, os CPs por vezes assumem uma posição de mediadores entre os diferentes sujeitos do âmbito escolar. Esses profissionais, mesmo que tenham lacunas em sua formação inicial e que a formação continuada oferecida para eles não seja a mais adequada, pois não responde diretamente aos desafios do seu trabalho cotidiano, a motivação permanente e a reflexão crítica sobre sua prática contribuem para qualificar sua atuação nas escolas.

Similarmente, foi possível notar que a atuação dos CPs é também marcada por ações de urgência nas demandas escolares, sendo visto como "faz tudo" ou como "bombeiros", que ora atuam com os professores e profissionais, mas que por vezes também assumem desvios de funções para não deixar lacunas na rotina escolar. Isso, ainda que seja um desafio permanente para os CPs, é algo que deve ser tratado a nível macro de políticas, que delimitem o espaço de atuação e comunguem esforços para a criação de uma cultura escolar de valorização do CP a partir da qualificação permanente de suas ações.

Finalizando, é importante salientar a validade da realização de pesquisas do tipo Estado da Arte. Este tipo de estudo permite mapear questões pertinentes para o desenvolvimento de determinada área de estudo, realizar discussões sobre determinados temas e buscar o aprofundamento sobre determinados conceitos. Sendo assim, a presente pesquisa logrou caracterizar a figura do CP, utilizando-se do descritor "coordenador pedagógico" em teses de doutorado presentes no CTD da CAPES. Realizar um estudo desta natureza nos permitiu observar com maior clareza a atuação profissional destes sujeitos, além de compreender o que vem sendo dito em pesquisas sobre seu trabalho. Isso, poderá ampliar olhares sobre a compreensão sobre os CPs e contribuir também para a realização de pesquisas futuras. 


\section{REFERÊNCIAS}

AMARAL, Míriam Matos. O trabalho do coordenador pedagógico e a formação continuada de professores centradas na escola inclusiva em Belém-PA. 2019. 236 f. Tese (Doutorado em Educação) - Universidade Federal do Pará. Belém, PA, 2019.

BEZERRA, Edneide da Conceição. A tecitura da ação do coordenador pedagógico da EJA: saberes necessários à mediação do trabalho docente em alfabetização. 2009. 258 f. Tese (Doutorado em Educação) - Universidade Federal do Rio Grande do Norte. Natal, RN, 2009.

BRUNO, Eliane Bambini Gorgueira. Os saberes das relações interpessoais e a formação inicial do coordenador pedagógico. 2006. 316 f. Tese (Doutorado em Psicologia da Educação) - Pontifícia Universidade Católica de São Paulo, São Paulo, SP, 2006.

CARLOS, Rinalda Bezerra. Um estudo sobre a formação continuada do coordenador pedagógico desenvolvida pelo CEFAPRO de Cáceres/MT. 2013. 180 f. Tese (Doutorado em Educação) Pontifícia Universidade Católica de São Paulo, São Paulo, SP, 2013.

CARVALHO, Maria Cristina Moraes. O programa escola de gestores da educação básica e a política de formação continuada para coordenadores pedagógicos: que coordenação pedagógica. 2020. 284 f. Tese (Doutorado em educação) - Universidade Católica de Petrópolis, Petrópolis, RJ, 2020.

CÔRREA, Barbara Raquel do Prado Gimenez. O cotidiano do coordenador pedagógico na visão da complexidade: práticas de formação continuada no cenário da educação infantil. 2016. 255 f. Tese (Doutorado em educação) - Pontifícia Universidade Católica do Paraná, Curitiba, PR, 2016.

DOMINGUES, Isaneide. O coordenador pedagógico e o desafio da formação contínua do docente na escola. 2009. 237 f. Tese (Doutorado em Educação) - Universidade de São Paulo, São Paulo, SP, 2009.

FREIRE, Paulo. Política e educação: ensaios. 5 ed. São Paulo: Cortez, 2001.

FREIRE, Paulo; SHOR, Ira. Medo e ousadia: o cotidiano do professor. Tradução de Adriana Lopes. 1. Ed. Rio de Janeiro: Paz e Terra, 2013.

GARCIA, Marilene. Formação continuada para coordenadores pedagógicos: e a escola, como fica? 2008. 198 f. Tese (Doutorado em Psicologia da Educação) - Pontifícia Universidade Católica de São Paulo, São Paulo, SP, 2008.

GARRIDO, Elsa. Espaço de formação continuada para o professor-coordenador. In: BRUNO, Eliane Bambini Gorgueira; ALMEIDA, Laurinda Ramalho de.; CHRISTOV, Luiza Helena da Silva. (org.). O coordenador pedagógico e a formação docente. 8. ed São Paulo: Edições Loyola, 2007.

GERHARDT, Tatiana Engel; et al. A estrutura do projeto de pesquisa. In: GERHARDT, Tatiana Engel; SILVEIRA, Denise Tolfo.(Org.). Métodos de Pesquisa. Porto Alegre: Editora da UFRGS, 2009.

GOMES, Romeu. A análise de dados em pesquisa qualitativa. In: MINAYO, Maria Cecília de Souza (Org). Pesquisa Social. 23.ed. Rio de Janeiro: Vozes, 2004.

LEITE, Vania Finholdt Angelo. A atuação da coordenação pedagógica em conjunto com os professores no processo de recontextualização da política oficial no $1^{\circ}$ ano do Ensino Fundamental no município do Rio de Janeiro. 2012; 160 f. Tese. (Doutorado em Educação) - Pontifícia Universidade Católica do Rio de Janeiro, Rio de Janeiro, RJ, 2012. 
MOLICA, Andrea Jamil Paiva. O professor especialista iniciante: contribuições do coordenador pedagógico para seu trabalho. 2014. 247 f. Tese (Doutorado em Educação) - Pontifícia Universidade Católica de São Paulo, São Paulo, SP, 2014.

MOSQUINI, Juliane do Nascimento. A mediação do coordenador pedagógico no desenvolvimento profissional de professores que ensinam matemática. 2019. 277 f. Tese (Doutorado em Educação) - Universidade Estadual Paulista, Presidente Prudente, SP, 2019.

OLIVEIRA, Jane Cordeiro de. Os coordenadores pedagógicos de escolas da Secretaria Municipal de Educação da cidade do Rio de Janeiro como mediadores das políticas curriculares. 2015. 178 f. Tese (Doutorado em Educação) - Pontifícia Universidade Católica do Rio de Janeiro, Rio de Janeiro, RJ, 2015.

OSHIRO, Katyuscia. Escola de tempo integral e os meandros da coordenação pedagógica no município de Campo Grande-MS. 2017. 151 f. Tese (Doutorado em educação) - Universidade Federal de Mato Grosso do Sul, Campo Grande, MS, 2017.

PALACIO, Olga Lúcia Londoño.; GRANADOS, Luis Facundo Maldonado; VILLAFÁÑEZ, Liccy Catalina Calderón. Guía para construir estados del arte. Bogotá: International Corporation of Networks of Knowledge, 2014.

PLACCO, Vera Maria Nigro de Souza; ALMEIDA, Laurinda Ramalho de; SOUZA, Vera Lúcia Trevisan de. O coordenador pedagógico e a Formação de Professores: Intenções, Tensões e Contradições. São Paulo: Fundação Victor Civita e Fundação Carlos Chagas, 2011.

TEIXEIRA, Cristiane de Sousa Moura. Ser o "faz-tudo" na escola: a dimensão subjetiva do trabalho do coordenador pedagógico. 2014. 261 f. Tese (Doutorado em Educação) - Universidade Federal do Piauí, Teresina, PI, 2014.

\section{Informações do(a)(s) autor(a)(es)}

Rocheli Regina Predebon Silveira

Secretaria de Educação do Estado do Rio Grande do Sul

E-mail: rocheli.silveira@hotmail.com

ORCID: http://orcid.org/0000-0001-9098-7985

Link Lattes: http://lattes.cnpq.br/5034728800362822

Agnaldo Mesquita de Lima Junior

Universidade Federal de Santa Maria (UFSM)

E-mail:Agnaldo-mesquita@hotmail.com

ORCID: https://orcid.org/0000-0002-5774-7303

Link Lattes: http://lattes.cnpq.br/4013378638360585

Maurício Aires Vieira

Universidade Federal do Pampa (UNIPAMPA)

E-mail:mauriciovieira@unipampa.edu.br 
ORCID: http://orcid.org/0000-0003-0737-9941

Link Lattes: http://lattes.cnpq.br/2009052579244052 